\title{
A study of women's preferences regarding the formulation of over-the-counter vaginal spermicides
}

Christiana Coggins

Christopher J. Elias

Ronachai Atisook

Mary T. Bassett

Virginie Ettiegne-Traore

See next page for additional authors

Follow this and additional works at: https://knowledgecommons.popcouncil.org/departments_sbsr-rh

Part of the Demography, Population, and Ecology Commons, Family, Life Course, and Society

Commons, and the International Public Health Commons

How does access to this work benefit you? Let us know!

\section{Recommended Citation}

Coggins, Christiana, Christopher J. Elias, Ronachai Atisook, Mary T. Bassett, Virginie Ettiegne-Traore, Peter D. Ghys, Laura Jenkins-Woelk, Earmporn Thongkrajai, and Nancy L. VanDevanter. 1998. "A study of women's preferences regarding the formulation of over-the-counter vaginal spermicides," Robert $\mathrm{H}$. Ebert Program on Critical Issues in Reproductive Health Publication Series. New York: Population Council. 


\section{Authors}

Christiana Coggins, Christopher J. Elias, Ronachai Atisook, Mary T. Bassett, Virginie Ettiegne-Traore, Peter D. Ghys, Laura Jenkins-Woelk, Earmporn Thongkrajai, and Nancy L. VanDevanter 


\section{A Study of Women's Preferences}

Regarding the Formulation of

\section{Over-the-Counter Vaginal Spermicides}




\title{
A Study of Women's Preferences
}

\section{Regarding the Formulation of}

\section{Over-the-Counter Vaginal Spermicides}

\author{
Christiana Coggins ${ }^{1}$ \\ Christopher J. Elias ${ }^{2}$ \\ Ronachai Atisook ${ }^{3}$ \\ Mary T. Bassett ${ }^{4}$ \\ Virginie Ettiègne-Traoré ${ }^{5}$ \\ Peter D. Ghys ${ }^{5 / 6}$ \\ Laura Jenkins-Woelk ${ }^{4}$ \\ Earmporn Thongkrajai ${ }^{7}$ \\ Nancy L. VanDevanter ${ }^{8}$
}

${ }^{1}$ Population Council, New York, NY, USA

${ }^{2}$ Population Council, Bangkok, Thailand

${ }^{3}$ Siraraj Family Health Research Center, Bangkok, Thailand

${ }^{4}$ University of Zimbabwe, Harare, Zimbabwe

${ }^{5}$ Projet RETRO-CI, Abidjan, Côte d'Ivoire

${ }^{6}$ Institute of Tropical Medicine, Antwerp, Belgium

${ }^{7}$ Khon Kaen University, Khon Kaen, Thailand

${ }^{8}$ Columbia University School of Public Health, New York, NY, USA 
The Population Council is an international, nonprofit, nongovernmental institution that seeks to improve the wellbeing and reproductive health of current and future generations around the world and to help achieve a humane, equitable, and sustainable balance between people and resources. The Council conducts biomedical, social science, and public health research and helps build research capacities in developing countries.

The Council's Robert H. Ebert Program on Critical Issues in Reproductive Health, established in 1988, responds to an awareness that many important reproductive health problems — and the ways women experience them— have been neglected by policymakers, program planners, and practitioners. Currently the Program focuses on several areas that merit special attention: improving the quality of services in reproductive health programs, managing unwanted pregnancy and preventing the consequences of unsafe abortion, devising new approaches to postpartum care to meet the health needs of the mother and child, and designing programs that address sexually transmitted diseases, including AIDS, within the larger context of women's reproductive health.

\section{Q Population Council}

The Robert H. Ebert Program

on Critical Issues in Reproductive Health

Population Council

One Dag Hammarskjold Plaza

New York, NY 10017 USA

(212) 339-0500

Fax: 212-755-6052

(C1998 by The Population Council, Inc.

Cover and text printed on recycled paper in the USA 


\section{Acknowledgments}

This publication was made possible through the Office of Population, Center for Population, Health \& Nutrition, Bureau for Global Programs, Field Support and Research, United States Agency for International Development, Cooperative Agreement No. CCP-3050-A-00-4013-00. The opinions expressed herein are those of the authors and do not necessarily reflect the views of the U.S. Agency for International Development.

We would like to express our appreciation to Charlotte Ellertson, Shelley Clark, Jessica Bull, Martha Brady, and Erica Gollub for their input into the study design, analysis and interpretation of findings.

Author responsible for correspondence:

Christiana Coggins, MPH

Staff Associate

Population Council

The Robert H. Ebert Program on

Critical Issues in Reproductive Health

One Dag Hammarskjold Plaza

New York, NY 10017 


\begin{abstract}
Objective: There is an urgent need for safe, effective and acceptable vaginal barrier methods for the prevention of sexually transmitted diseases (STDs), including HIV. A variety of existing spermicides have the potential to be used both for prevention of STDs and unwanted pregnancy. Unfortunately, very little is known about formulation preferences and the desirable characteristics of vaginal preparations among the diverse populations of women who would potentially use these products. As product acceptability ultimately determines compliance and use-effectiveness, such information is essential to guide the development and formulation of new microbicidal vaginal products. In this study, we explored vaginal spermicidal preparations containing nonoxynol-9 and the characteristics that influence user preferences for three formulations. We also studied the risk of vaginal and cervical irritation associated with low to moderate use of products containing nonoxynol-9.
\end{abstract}

Methods: One hundred forty-five sexually active women were enrolled in five sites (Côte d'Ivoire, Zimbabwe, USA, and Thailand - two sites: one rural, one urban) and asked to use three different vaginal spermicide preparations containing nonoxynol-9 (a gel, a film, and a suppository). Each volunteer used each product for four weeks. Structured interviews and clinical examinations were conducted at biweekly clinic visits. Prior and to and following product use, women participated in focus group discussions to explore their knowledge, beliefs, and practices surrounding vaginal product use.

Results: Women enrolled in the New York City site were almost evenly divided in their preferences of the three formulations; most women enrolled in the Thai sites ranked the film as their preferred formulation (followed by the gel) due largely to the fact that it was easy to use, not too messy, and did not produce a lot of discharge; most of the women enrolled in Zimbabwe also ranked the film as their favorite, followed by the gel, because it was considered the least messy and provided the least amount of lubrication. In Côte d'Ivoire, gel was the preferred formulation, followed closely by film. In general, the suppository was reported to be most messy, with the tendency to melt prior to insertion in hotter climates. No significant irritation or lesions resulted from product use in any of the sites. Almost every woman reported that her partner was aware of, and supportive of, her participation in the study.

Conclusion: The formulation preferences of women should be considered in the development and introduction of vaginal microbicides: the specific characteristics of vaginal products and their effect on sexual pleasure and communication will strongly determine the acceptability - and ultimately the use-effectiveness - of female-controlled STD-prevention methods. 


\section{CONTENTS}

Introduction

Materials and Methods ___ 1

Study locations/sample ___ 1

Products used _ 2

Study procedure _ 2

Results _ 3

Socio-demographic characteristics __ 3

Vaginal product and condom use history __ 4

Partner's knowledge of product use __ 4

Experience with study products

Discussion _ 9

References _ 12 


\section{Introduction}

There is an urgent need for safe, effective, and acceptable vaginal barrier methods for the prevention of sexually transmitted diseases (STDs), including HIV. As product acceptability ultimately determines use-effectiveness, developing and introducing effective vaginal products for prevention of unwanted pregnancy and/or STD infection requires insight into users' perspectives (Elias et al., 1996). Research exploring the acceptability of woman-controlled barrier methods such as the female condom and the diaphragm (Do Lago et al., 1995; Gollub et al., 1995) has shown us that adoption of new methods is often a function of the kind of counseling that women receive with the new method, as well as having an opportunity to get accustomed to the method. With the exception of two studies which looked at film, foam, foaming tablets, and suppositories in four countries in Latin America and East Africa (Steiner et al., 1995; Hira et al., 1995), little research has explored what constitutes the desirable characteristics of vaginal preparations among the diverse populations of women who would potentially use these products. In addition to focusing on the kind of counseling that women receive, information regarding formulation preferences is essential for guiding the development of new vaginal preparations, as well as the broader application of existing spermicides.

In this study, we sought to explore the characteristics of existing vaginal products - a gel, a suppository, and a film - that influence user preferences for various formulations. Because of the known irritating properties of nonoxynol-9 (Roddy et al., 1993; Kreiss et al., 1992) we also sought to further knowledge on the risk of irritation to the vagina and cervix potentially associated with low to moderate use of spermicidal products containing nonoxynol-9.

\section{Materials and Methods}

\section{Study locations/sample}

To learn from a range of cultural norms relating to vaginal formulation preferences, we included a diverse group of study sites. These included the Projet RETRO-CI in Abidjan, Côte d'Ivoire; Africa; the Siriraj Family Health Research Center in Bangkok, Thailand; the University of Zimbabwe in Chitungwiza, a township outside of Harare, Zimbabwe; the University of Khon Kaen in Northeastern Thailand; and the Columbia University School of Public Health in New York City. A convenience sample of women was recruited at research centers via fliers and word of mouth or through health care facilities 
(e.g., antenatal/MCH clinics in Zimbabwe). To avoid the potential for irritation resulting from frequent use of nonoxynol-9 containing products, only women whose average coital frequency was one or fewer acts of intercourse per day were eligible for enrollment. Except for the Khon Kaen site, which recruited women from a village setting, all of the participants were drawn from urban populations.

\section{Products used}

Study participants used three different vaginal preparations (see Table 1), including the Vaginal Contraceptive Film ${ }^{\circledR}$ (Apothecus Pharmaceutical Corp., Oyster Bay, NY) containing 70 milligrams of nonoxynol-9; a vaginal suppository (Ortho Conceptrol ${ }^{\circledR}$ Vaginal Inserts) with 150 milligrams of nonoxynol-9, and a vaginal gel in a pre-filled applicator (Ortho Conceptrol ${ }^{\circledR}$ Gel) containing 200 milligrams of nonoxynol-9, both made by Advanced Care Products (Ortho Pharmaceutical Corp., Raritan, NJ). ${ }^{1}$

Table 1

Products Used in the Study

\begin{tabular}{||l|l||}
\hline Product used & Nonoxynol-9 \\
\hline \hline Apothecus Vaginal Contraceptive Film ${ }^{\circledR}$ & $70 \mathrm{mg}$ \\
\hline Ortho Conceptrol ${ }^{\circledR}$ Gel & $200 \mathrm{mg}^{1}$ \\
\hline Ortho Conceptrol ${ }^{\circledR}$ Vaginal Inserts & $150 \mathrm{mg}$ \\
\hline \hline
\end{tabular}

\section{Study procedure}

Women were counseled to use the products together with a male latex condom during each act of vaginal intercourse. The study employed a crossover design where every participant used each product for a four-week period, during which time they were asked to report to the study center every two weeks for an interview and pelvic examination with speculum for visualization of the cervix and vagina. Women's experiences with product use, as well as any evidence of vulvar abnormality, cervical or vaginal discharge, cervicitis, or mucosal irritation, were coded on the case record forms. Characteristics of vaginal discharge recorded included color, quantity, odor, and $\mathrm{pH}$. Cervical discharge

\footnotetext{
${ }^{1}$ In our lab we found that only $100-120 \mathrm{mg}$ was actually dispensed from the applicator.
} 
was considered abnormal when described as purulent, mucopurulent or bloody. We defined cervicitis as observation of inflammation of the cervical mucous membrane. Using standard statistical software (SPSS Version 6.1), we compared symptomatic reports with clinical signs using $\mathrm{X}^{2}$ tests and Fisher's exact texts. Significance was designated as $\mathrm{p}<0.05$. In many cases, however, the numbers were very small and formal statistical comparisons were not attempted.

Prior to and following product use, all women participated in focus group discussions and structured interviews to assess their knowledge, practices, and preferences regarding each vaginal formulation. Women were asked to record each act of intercourse in a coital log where they also noted whether the study product and/or condoms were used.

\section{Results}

\section{Socio-demographic characteristics}

The mean age of the 145 women participating in this study ranged from 25 in Abidjan to 37 in Khon Kaen (see Table 2). In the two Thai sites, and in Chitungwiza, nearly all of the women were married; whereas in Abidjan and New York City married women constituted only 17 and 42 percent of the sample, respectively. The low figure in Abidjan

Table 2

Selected Characteristics of Study Populations

\begin{tabular}{||l|c|c|c|c|c||}
\hline & $\begin{array}{c}\text { Abidjan, } \\
\text { Côte } \\
\text { d'Ivoire } \\
\mathbf{n = 3 1}\end{array}$ & $\begin{array}{c}\text { Bangkok, } \\
\text { Thailand } \\
\mathbf{n = 2 5}\end{array}$ & $\begin{array}{c}\text { Chitungwiza, } \\
\text { Zimbabwe } \\
\mathbf{n = 2 2}\end{array}$ & $\begin{array}{c}\text { Khon } \\
\text { Kaen, } \\
\text { Thailand } \\
\mathbf{n = 3 6}\end{array}$ & $\begin{array}{c}\text { New York } \\
\text { City, } \\
\text { USA } \\
\mathbf{n = 3 1}\end{array}$ \\
\hline \hline Age (mean) & 25 & 30 & 32 & 37 & 30 \\
\hline Married (\%) & $17 \%$ & $100 \%$ & $96 \%$ & $100 \%$ & $42 \%$ \\
\hline $\begin{array}{l}\text { Coital frequency in } \\
\text { the month preceding } \\
\text { the study (mean) }\end{array}$ & 4 & 5 & 18 & 5 & 8 \\
\hline Parity (mode) & 2 & 1 & 4 & 3 & 1 \\
\hline $\begin{array}{l}\text { Ever tried to } \\
\text { convince partner to } \\
\text { use condoms (\%) }\end{array}$ & $63 \%$ & $40 \%$ & $79 \%$ & $27 \%$ & $97 \%$ \\
\hline $\begin{array}{l}\text { Always uses } \\
\text { condoms with } \\
\text { partner (\%) }\end{array}$ & $0 \%$ & $0 \%$ & $9 \%$ & $0 \%$ & $55 \%$ \\
\hline \hline
\end{tabular}


may reflect a high prevalence of unofficial—or commonlaw-marriage in Côte d'Ivoire. The mean coital frequency in the month prior to the study ranged from a low of four in Abidjan to a high of 18 in Chitungwiza. Parity ranged from one in New York City and Bangkok to a high of four in Chitungwiza.

\section{Vaginal product and condom use history}

There was considerable variation in women's previous experience with vaginal products, as reflected in women's prior use of spermicidal products or vaginal tampons. When asked why they might use vaginal products in the future, women from the four sites that reported data for this question stated that the primary reasons would be for protection from infection alone (40 percent), protection from pregnancy alone (13 percent), or both (44 percent). ${ }^{2}$.

A significant proportion of women in New York and the two African sites had tried in the past to convince their regular partners to use condoms (see Table 2). Consistent condom use, however, was reported by only 55 percent of women in New York City, nine percent in Chitungwiza, and no women in Abidjan, Bangkok, or Khon Kaen. ${ }^{3}$ Many women reported that their partners refused to use condoms because they did not want to contracept. During the study, the percentage of women whose partners used condoms during use of the study product was low, and was about the same regardless of which product the woman was using $(26,29$, and 30 percent, respectively, for film, gel and suppository).

\section{Partner's knowledge of product use}

When asked whether they were able to use the study products without their partner's knowledge, most women in this study reported that they preferred to inform their partners that they were using vaginal products - both in the context of the study, and in a hypothetical, future framework (see Table 3). Only roughly one-quarter of the women chose not to inform their partners, with even lower percentages in the Thai sites. Most women preferred telling their partners at the outset of the study, in case they or their

\footnotetext{
${ }^{2}$ The Khon Kaen site did not report data for this question and 3\% of participants at the other four sites were "not sure" or had missing data for this question.

${ }^{3} \mathrm{New}$ York site investigators felt that, given the probability that participants volunteering for this study are particularly interested in barrier prevention methods, the consistent condom use levels reported for New York may actually be substantially higher than in the general population.
} 
Table 3

Able to Use Product Without Partner's Knowledge

\begin{tabular}{||l|c|c|c|c|c||}
\hline \hline & $\begin{array}{c}\text { Abidjan, Côte } \\
\text { d'Ivoire } \\
\mathbf{n = 3 1}\end{array}$ & $\begin{array}{c}\text { Bangkok, } \\
\text { Thailand } \\
\mathbf{n = 2 5}\end{array}$ & $\begin{array}{c}\text { Chitungwiza, } \\
\text { Zimbabwe } \\
\mathbf{n = 2 2}\end{array}$ & $\begin{array}{c}\text { Khon Kaen, } \\
\text { Thailand } \\
\mathbf{n = 3 6}\end{array}$ & $\begin{array}{c}\text { New York } \\
\text { City, USA } \\
\mathbf{n = 3 1}\end{array}$ \\
\hline \hline Film & $40 \%$ & $0 \%$ & $20 \%$ & $3 \%$ & $15 \%$ \\
\hline Gel & $25 \%$ & $4 \%$ & $17 \%$ & $14 \%$ & $27 \%$ \\
\hline Suppository & $20 \%$ & $0 \%$ & $14 \%$ & $4 \%$ & $26 \%$ \\
\hline
\end{tabular}

partners subsequently experienced problems with a particular product. In Chitungwiza women were particularly concerned about having to explain the presence of a product if her partner detected it. Others said that their partners supported them in using vaginal products, especially if vaginal product use was perceived to enhance sexual frequency or pleasure. There was no correlation between formulation preferences and the desire to hide product use from one's partner.

\section{Experience with study products}

In most cases, women found the suppository to be the messiest and, therefore, least desirable of the formulations: it tended to melt at the tropical ambient temperatures of several of the study sites and, consequently, needed refrigeration in order to prevent melting prior to insertion (see Table 4).

Table 4

Women's Preferences for Products, by Site

\begin{tabular}{||l|c|c|c|c|c|c||}
\hline & $\begin{array}{c}\text { Abidjan, Côte } \\
\text { d'Ivoire } \\
\mathbf{n = 3 1}\end{array}$ & $\begin{array}{c}\text { Bangkok, } \\
\text { Thailand } \\
\mathbf{n = 2 5}\end{array}$ & $\begin{array}{c}\text { Chitungwiza, } \\
\text { Zimbabwe } \\
\mathbf{n = 2 2}\end{array}$ & $\begin{array}{c}\text { Khon Kaen, } \\
\text { Thailand } \\
\mathbf{n = 3 6}\end{array}$ & $\begin{array}{c}\text { New York } \\
\text { City, USA } \\
\mathbf{n}=\mathbf{3 1}\end{array}$ & All sites \\
\hline $\begin{array}{l}\text { Product liked } \\
\text { most }\end{array}$ & gel & film & film & film & gel & film \\
\hline $\begin{array}{l}\text { Product liked } \\
\text { least }\end{array}$ & suppository & suppository & gel & suppository & film & suppository \\
\hline
\end{tabular}

As with the earlier three-country study (Steiner et al., 1995), film was the overall preferred formulation in three of the five sites in that it was considered to be the most 
"natural" and was liked by many of the women's partners. Women in Khon Kaen, Bangkok, Chitungwiza, and Abidjan all stated that they liked the film especially, due to the fact that it left the vagina feeling "tight" or "fit." Indeed, preferences were often related to perceptions of "wet" versus "dry" (see Table 5). Due to the fact that the film has a tendency to stick to damp fingers, however, it was considered the most difficult to insert by many users. For those women who experienced initial difficulty in inserting the film, however, their confidence and ability to use this product increased substantially with experience and supportive counseling.

The most preferred formulation in New York and Abidjan, the gel was generally deemed the easiest to apply and had an advantage of not requiring a waiting time following

Table 5

Selected Product Characteristics Described by Study Participants

\begin{tabular}{||l|l|l||}
\hline \hline & Advantages & Disadvantages \\
\hline \hline Film & $\begin{array}{l}\text { Least messy } \\
\text { Easy to conceal/dispose of } \\
\text { Can't feel it when it's in } \\
\text { Enhanced sexual pleasure }\end{array}$ & $\begin{array}{l}\text { Tends to stick to fingers during } \\
\text { application } \\
\text { Long wait for it to melt prior to } \\
\text { intercourse }\end{array}$ \\
\hline $\begin{array}{l}\text { Gel with } \\
\text { applicator }\end{array}$ & $\begin{array}{l}\text { No waiting time before product is } \\
\text { effective } \\
\text { Applicator precludes need to touch } \\
\text { oneself directly } \\
\text { Enhanced sexual pleasure }\end{array}$ & $\begin{array}{l}\text { Often runny } \\
\text { Applicator painful to use } \\
\text { Applicator difficult to conceal/ } \\
\text { dispose of }\end{array}$ \\
\hline Suppository & $\begin{array}{l}\text { Lubricating } \\
\text { Small, easy to conceal/dispose of }\end{array}$ & $\begin{array}{l}\text { Tendency to melt at warm ambient } \\
\text { temperatures } \\
\text { Creates a lot of messy discharge }\end{array}$ \\
\hline
\end{tabular}

insertion. It was also preferred by older women in the Khon Kaen site specifically because of its lubricant qualities. Many other women, however, complained of excessive lubrication and "runniness" following intercourse with the gel product.

We found that preferences after actual use did not correlate well with those expressed in hypothetical pre-use focus group discussions, especially in those sites where women had little prior experience with vaginal product use. For example, some participants were "intrigued" by unfamiliar products and predicted that they would like them best (e.g., 
women in New York thought the film was wonderfully small, and women in Bangkok were quite taken with the gel's applicator). On the other hand, women's hypothetical preferences were often informed by what they were already familiar with. For example, in Khon Kaen women thought that they would like the suppository because they were familiar with the use of suppositories for the treatment of vaginal yeast infections whereas they had never seen a vaginal film or applicator before. Following actual product use, however, the characteristics that women often found interesting, familiar or appealing no longer mattered in their overall ranking of the product.

In discussions both before and after product use, women felt strongly that vaginal products should be formulated so as to not interfere with sexual pleasure. In fact, in three of the sites (Abidjan, Chitungwiza, and Khon Kaen), women favored some products because they enhanced sexual pleasure. In general, reports of the partners' and women's reactions to the different products reinforced each other.

Disposal was a major concern in Zimbabwe where women reported burning the used applicators and packaging to avoid having neighbors and/or children find evidence of their use. Similarly, participants in Khon Kaen expressed concern about their need to keep the suppositories in the refrigerator where other family members could see them.

There were often trade-offs regarding product characteristics. For example, some women liked the ease of insertion of the gel, but also felt it was too messy. Several of these women compensated for this by decreasing the volume of gel they applied. Some women reported that use of certain products resulted in increased frequency of intercourse. However, overall product preference was not a function of coital frequency. Of interest, women in some sites either perceived that the products had medicinal or hygienic effects (Chitungwiza) or reported an improvement in chronic genital symptoms, such as pruritus, after product use (Khon Kaen). Despite specific drawbacks to each formulation, study participants expressed great interest in the products, and many stated that they would continue to use any of them - even their least preferred formulations - if they were available and approved for STD prevention.

There was considerable variation between sites in regard to reports of "some," "moderate," and "high" levels of discomfort or irritation due to product use (see Table 6). Women in most sites reported the least discomfort in using the film, and the most in gel use. 
Table 6

Reported Discomfort or Irritation with Product Use

\begin{tabular}{|l|c|c|c|c|c|c||}
\hline \hline & $\begin{array}{c}\text { Abidjan, } \\
\text { Côte } \\
\text { d'Ivoire } \\
\mathbf{n = 3 1}\end{array}$ & $\begin{array}{c}\text { Bangkok, } \\
\text { Thailand } \\
\mathbf{n = 2 5}\end{array}$ & $\begin{array}{c}\text { Chitungwiza, } \\
\text { Zimbabwe } \\
\mathbf{n = 2 2}\end{array}$ & $\begin{array}{c}\text { Khon Kaen, } \\
\text { Thailand } \\
\mathbf{n = 3 6}\end{array}$ & $\begin{array}{c}\text { New York } \\
\text { City, USA }\end{array}$ & All sites \\
$\mathbf{n = 3 1}$ & $\mathbf{n = 1 4 5}$ \\
\hline \hline Film & $4 \%$ & $0 \%$ & $5 \%$ & $3 \%$ & $7 \%$ & $4 \%$ \\
\hline Gel & $0 \%$ & $21 \%$ & $11 \%$ & $36 \%$ & $19 \%$ & $20 \%$ \\
\hline Suppository & $5 \%$ & $21 \%$ & $5 \%$ & $15 \%$ & $11 \%$ & $12 \%$ \\
\hline \hline
\end{tabular}

Analysis of clinical observations, however, indicates that irritation of the cervix or vagina was fairly uncommon (see Table 7). Among women's reports of symptoms and clinical findings for each product use group, there was no association between clinical irritation and reported symptoms (Fisher's exact test for intervals of gel use $(\mathrm{p}=1.00)$, for intervals of film use ( $\mathrm{p}=0.43)$, or for intervals of suppository use $(\mathrm{p}=0.07)$ ). Despite differences in partners' preferences, which were reflected in women's own stated preferences, reported partner irritation was fairly low across the products (six, eleven, and nine percent of male partners reported irritation with film, gel, and suppository, respectively).

Table 7

Number of Clinical Signs Observed/Total Number of Clinical Visits

\begin{tabular}{||l|c|c|c|c|c|c||}
\hline & $\begin{array}{c}\text { Vulvar } \\
\text { abnormality }\end{array}$ & $\begin{array}{c}\text { Vaginal } \\
\text { discharge }\end{array}$ & $\begin{array}{c}\text { Cervical } \\
\text { discharge }^{\mathrm{b}}\end{array}$ & Cervicitis $^{\text {Pain on bi-weekly }}$ & manual exam & Total \\
\hline \hline Baseline $^{\mathrm{a}}$ & $3 / 145$ & $4 / 145$ & $4 / 145$ & $0 / 145$ & $3 / 145$ & $14 / 145$ \\
\hline Film & $3 / 290$ & $3 / 290$ & $11 / 290$ & $1 / 290$ & $1 / 290$ & $19 / 290$ \\
\hline Gel & $1 / 290$ & $5 / 290$ & $9 / 290$ & $1 / 290$ & $0 / 290$ & $16 / 290$ \\
\hline Suppository & $2 / 290$ & $0 / 290$ & $8 / 290$ & $0 / 290$ & $0 / 290$ & $10 / 290$ \\
\hline
\end{tabular}

${ }^{\mathrm{a} C}$ Clinical observations at enrollment.

bIncluded cervical discharge described as "purulent," "mucopurulent," and "bloody." 


\section{Discussion}

Overall, we observed considerable variation in users' perspectives and formulation preferences both within and between sites. As with the earlier three-country study (Steiner et al., 1995), film was the overall preferred formulation. Nevertheless, cultural norms affected specific preferences for relative "dryness" of the formulations, and generational differences, even within the same site, influenced the degree of lubrication considered desirable. This suggests that, in the development of new vaginal microbicides, multiple products will be required to meet the needs of all users.

Because of the wide range of cultural norms governing desirable fertility levels, and given women's differing personal expectations and needs, study participants expressed considerable interest in the possibility of using a vaginal microbicide that would be nonspermicidal. Although it could be argued that most women, at any given point in their lives, probably do not want to become pregnant, it can also be noted that nearly every woman, at some point in her life, does want to conceive - preferably without putting herself at risk of infection. Ideally, both contraceptive and non-contraceptive products should be pursued in research and development efforts.

Storage, application and disposal issues must be taken into consideration as well. With regard to packaging, many study participants commented favorably on the ease with which they were able to conceal the film, both in storage and in disposal. It will be important to consider the amount of excess "packaging" that characterizes a given product. In almost every site, at least some of the women reported that they and their partner enjoyed using the products because their use was seen as sexy: for those women, a product that is perceived as enhancing sexual pleasure is more likely to be used. In a few sites, women felt that the products "cured" them of various vaginal complaints even though they were told what the products were for. Clearly, the "trade-offs" between promoting a product for disease prevention versus increasing sexual pleasure or vaginal health must be further explored.

As noted above, and as has been observed in other low-frequency studies of nonoxynol-9 use (Feldblum, 1996), the numbers of women reporting any kind of discomfort were very low, as were the number of women with clinical signs of irritation. Although women were encouraged to come in to the clinic at any time they experienced discomfort with any of the products, we observed that women only came in for their scheduled two-week visits. We must therefore be cautious in drawing conclusions about a lack of correlation 
between clinical signs and symptoms, given that women may indeed have had clinical signs of irritation at the time they were experiencing symptoms that had cleared up by the time they came in for their examination. Such a lack of correlation in lower frequency use of nonoxynol-9 was also observed in a previous study (Roddy et al., 1993).

Women in this study, many of whom were family planning clients or hospital employees, expressed little interest in covert methods. In fact, many of the participants stated that they "wouldn't dream" of hiding product use from their partner. Women in partnerships characterized by higher levels of violence, coercion, or commerce, however, might have a greater need for products that could be used without a partner's knowledge. It is also possible that covert use would be more common outside the context of a research study. Despite the fact that products such as those employed in the study have been available in several of the study sites as over-the-counter spermicides for many years, the frequent clinic visits and intense clinical observations of this study gave some participants the impression of "experimental" product use. A few women mentioned in the focus group discussions that their partners expressed some concern about the nature of such experimentation. The study may have thus introduced a concern for gaining partner consent that may not exist when products are commercially available.

For this group of women, partner's perceptions of product characteristics and the dynamics of partner communication proved to be very important. It is therefore critical to explore men's attitudes and beliefs regarding vaginal microbicide use more explicitly in future studies.

A greater understanding of users" perspectives and preferences will help in the preclinical development of new vaginal products: information on how, why and whether women will use new products is essential to help us to create a product that will actually be accepted and used. Yet, as evident in other studies (Do Lago, 1995; Gollub, 1995), there is also a need to consider the counseling and information needs of potential users and the important role of service providers. Ultimately, changing the products may only be one half of the equation: we must also learn more about the best ways to introduce and support products within service delivery programs.

Given the trade-offs that women and their partners face in using vaginal products, we must also learn more about the dynamics of actual product use. Few people will adhere strictly to package instructions, especially when using products outside the context of a clinical study. For instance, if women are going to decrease the volume of vaginal applications because the product is otherwise too messy, we must know this in order to 
ensure that dosage is adequate under real use conditions. As with other user-controlled methods, product acceptability is a central determinant of use-effectiveness. Ultimately, the development and introduction of any new vaginal microbicide will need to take into careful consideration the kinds of findings of this and similar studies, in order to ensure that women are armed with the best information and products available to protect themselves from infection. 


\section{References}

Do Lago, T.D., R.M. Barbosa, S. Kalckmann, W.V. Vilela, and S. Gohiman. 1995. Acceptability of the diaphragm among low-income women in São Paulo, Brazil, International Family Planning Perspectives, 21:114-118.

Elias, C.J. and C. Coggins. 1996. Female-controlled methods to prevent sexual transmission of HIV, AIDS, 10 (suppl 3):S43-S51.

Feldblum, P.J. 1996. Self-reported discomfort associated with use of different nonoxynol9 spermicides, letter in Genitourinary Medicine, Vol. 71, 6:451-452.

Gollub, E.L., Z. Stein, and W. El-Sadr. 1995. Short-term acceptability of the female condom among staff and patients at a New York City Hospital, Family Planning Perspectives, 27:155-158.

Hira, S.K., A.B. Spruyt, P.J. Feldblum, M.R. Sunkutu, L.H. Glover, and M.J. Steiner. 1995. Spermicide acceptability among patients at a sexually transmitted disease clinic in Zambia, American Journal of Public Health, 85:1098-1103.

Kreiss, J., E. Ngugi, K.K. Holmes, et al. 1992. Efficacy of nonoxynol-9 contraceptive sponge use in preventing heterosexual acquisition of HIV in Nairobi prostitutes, Journal of the American Medical Association, 268:477-82.

Roddy, R.E., M. Cordero, C. Cordero, and J.A. Fortney. 1993. A dosing study of nonoxynol-9 and genital irritation, International Journal of STD \& AIDS, 4:165-170.

Steiner, M.J., A.B. Spruyt, C. Joanis, et al. 1995. Acceptability of spermicidal film and foaming tablets among women in three countries, International Family Planning Perspectives, 21:104-107. 
